\title{
A Lifeline for a Hopeless Tooth - A Multidisciplinary Approach
}

\author{
Rajesh Shetty ${ }^{1}$, Karkala Syed Suhaim², Shriya Deepak Jain ${ }^{3}$, Sanath Kumar Shetty ${ }^{4}$, Mariyam Zehra ${ }^{5}$ \\ 1, 2, 3, 4, 5 Department of Prosthodontics, Yenepoya Dental College, Yenepoya University, \\ University Road, Deralakatte, Mangalore, Karnataka, India.
}

\section{INTRODUCTION}

Restoration of traumatic teeth with complicated crown root fracture poses many challenges to the clinicians. When the fracture line is below the level of gingiva, the prognosis of such fractured tooth is considered questionable or hopeless. Treating such cases is also challenging as they are associated with loss of ferrule and compromised biological width. Preservation of such diseased natural teeth usually involves a multi-disciplinary approach involving endodontic therapy, periodontal crown lengthening and / or orthodontic extrusion followed by prosthetic rehabilitation.

Tooth injuries and complicated tooth fractures especially in the aesthetic region pose a great challenge to the clinician. ${ }^{1}$

When the fracture line extends at or below the level of cement enamel junction, the prognosis of such tooth is considered questionable or hopeless; they are usually associated with the loss of ferrule and compromised biological width, and therefore restoration of such teeth becomes a great challenge.

To ensure functional longevity, endodontically treated teeth with less coronal structure must have at least $5 \mathrm{~mm}$ of tooth structure coronal to the crestal bone. Three milli meters of tooth structure is needed to maintain a healthy soft tissue complex, and $2 \mathrm{~mm}$ of coronal tooth structure incisal to the preparation finish line is necessary to ensure structural integrity. ${ }^{2}$

There are mainly two reasons why a tooth extraction should be avoided: Structural reasons and psychological stress associated with extraction. Psychological stress can be in the form of financial stresses associated with extraction and rehabilitation of the same and fear of post-traumatic pain.

Extraction of tooth is also followed by aesthetic challenges as it may lead to hard and soft tissue resorption as the healing architecture is unpredictable.

In this case report a simple yet effective treatment is presented for a 21-year-old female patient with a chief complaint of clinical tooth fracture in relation to 44 . After thorough clinical and radiographic examination, it was decided to reinforce the use of flexible glass fibre post and incorporate the same as tags to engage $E$ chain to facilitate orthodontic tooth extrusion followed by prosthetic rehabilitation.

The purpose of this case report is to describe the use of a simple chair side technique for a tooth fractured at the level of cementoenamel junction (CEJ) with forced tooth eruption.
Corresponding Author: Dr. Shriya Jain,

C Block, Gardeynia Hostel, Yenepoya University, Mangalore - 575018,

Karnataka, India.

E-mail:shriyajjain@gmail.com

DOI: $10.14260 / j e m d s / 2021 / 197$

How to Cite This Article:

Shetty R, Suhaim KS, Jain SD, et al. A lifeline for a hopeless tooth - a multidisciplinary approach. J Evolution Med Dent Sci 2021;10(12):915-917, DOI: 10.14260/jemds/2021/197

Submission 09-11-2020,

Peer Review 27-01-2021

Acceptance 04-02-2021,

Published 22-03-2021.

Copyright (c) 2021 Rajesh Shetty et al. This is an open access article distributed under Creative Commons Attribution License [Attribution 4.0 International (CC BY 4.0)] 


\section{PRESENTATION OF CASE}

A 21-year-old female patient reported to the Department of Prosthodontics with a chief complaint of fractured tooth structure and desired the rehabilitation for the same. On examination it was seen that tooth number 44 was associated with dislodged restoration and insufficient clinical tooth structure measuring approximately $3 \mathrm{~mm}$ buccally and lingually the fracture line had extended at the level of free gingival margin. After detailed case history recording it was concluded that patient had undergone endodontic treatment with respect to 44,2 years back but discontinued the treatment thereafter.

\section{DISCUSSION OF MANAGEMENT}

Multiple treatment options were discussed with the patient and it was decided to retain and rehabilitate the same tooth as the patient was not willing for extraction. Patient was explained about tooth extrusion as the treatment of choice and consent for the same was obtained.
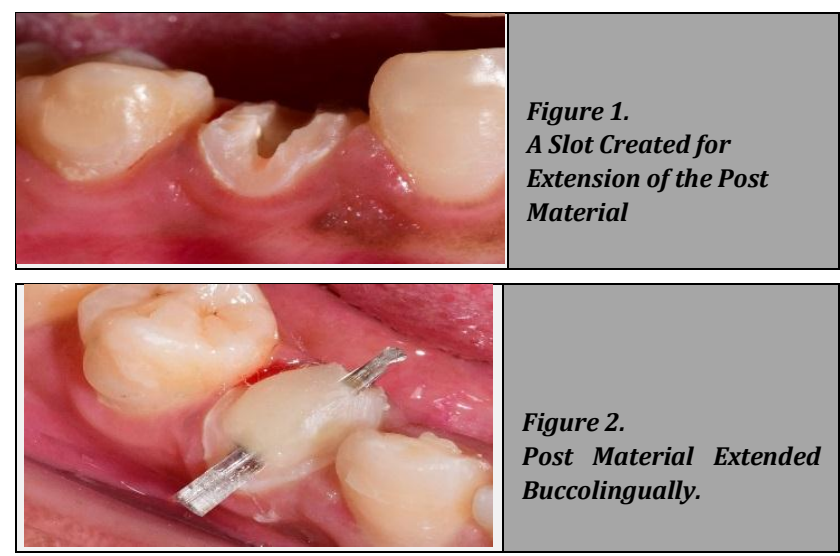

Figure 2.

Post Material Extended Buccolingually.

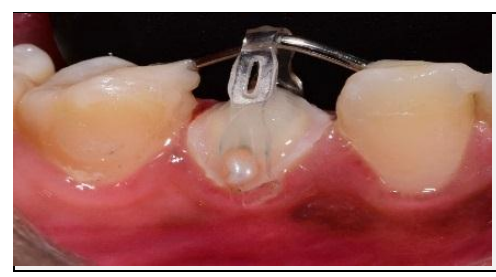

Figure 3.

A 19 Gauge Stainless Steel Wire was Placed at the Occlusal Third, and $E$ Chain Engaged on to the Extended Post Material.

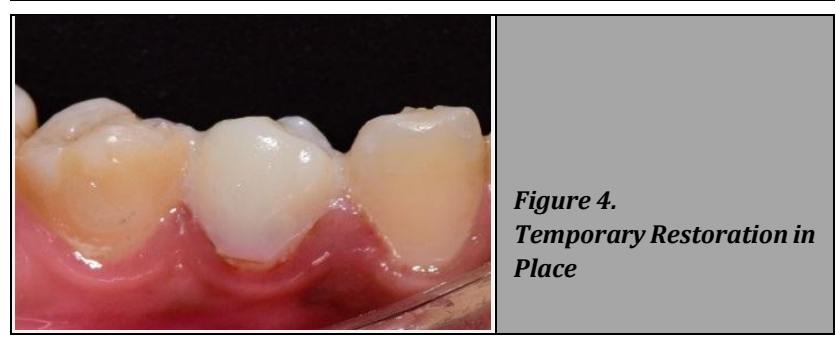

Pre-operative radiograph revealed adequate obturation with no signs of peri apical pathology. The root length was assessed, and post space preparation was done with Gates Glidden bur. $1 / 3^{\text {rd }}$ apical gutta percha was left and the rest of the obturating material was removed.

A flexible glass fibre post, everStick $®$ POST (GC) size 0.9 $\mathrm{mm}$ was used as a post material and cemented using ParaCore ${ }^{\circledR}$ (COLTENE). The fibre post material was extended buccally and lingually, and again reinforced with the same core material (ParaCore ${ }^{\circledR}$ (COLTENE)) (Figure 1, 2). Based on the fracture line lingually it was decided to extrude the tooth $3 \mathrm{~mm}$ above the CEJ.

A 19-gauge stainless steel wire was placed at the occlusal third, horizontally between the distal of the tooth anterior and mesial of the tooth posterior to the subject tooth using the flowable composite material (Filtek ${ }^{\mathrm{TM}}$ Z350 XT Universal Restorative-3M ESPE). An E chain was engaged onto the extended post material buccolingually (Figure 3).

The E chain was changed every 15 days till the desired clinical tooth structure was obtained. The desired position of the tooth was obtained after 3 months and after an initial stabilising period the tooth was prepared, and temporary restoration placed (Figure 4). The tooth was assessed for another 15 days. Final impression was then made, and definitive prosthesis cemented.

\section{DISCUSSION}

Post and cores have been the treatment of choice for endodontically treated teeth only when $1 \mathrm{~mm}$ of healthy supra gingival tooth structure is available to create ferrule. A ferrule is a band that encircles the external diameter of residual tooth structure. ${ }^{3}$ In cases where there is insufficient tooth structure a tooth can be orthodontically extruded to increase the length of the clinical tooth structure for the ferrule effect if the fracture line extends below the free gingiva, and also if the condition and length of the tooth root is sufficient enough to support the coronal restoration. ${ }^{4-6}$

In this clinical situation, there were two options for the rehabilitation: Extraction of the tooth followed by replacement or forced tooth extrusion followed by rehabilitation. Tooth extrusion was considered in this scenario as the patient did not consent to undergo extraction.

There are many types of post materials available in the market. The post that was selected for this patient was everStick ${ }^{\circledR}$ POST (GC). It had several advantages over the other traditionally used posts. It is flexible therefore it can adapt to the root canal surface which helps in the conservation of root canal dentin thereby preventing the perforation of the dentinal walls. ${ }^{7}$ It can also overcome the disadvantage associated with the fracture of the metal post. ${ }^{8}$ The post was extended coronally to stabilise the coronal core material. Taking advantage of the material flexibility, the same post was used to create buccal and lingual tags to engage the $\mathrm{E}$ chain. The resultant post and core had a stable monoblock structure.

Studies have also stated that there is a better micromechanical bonding between the post and the core with composite material. It has modulus of elasticity similar to dentin and has shown to have improved mechanical properties after curing. ${ }^{9}$

Authors recommend a maximum force of $30 \mathrm{~g}$ for slow orthodontic extrusion whereas a maximum force of $50 \mathrm{~g}$ for

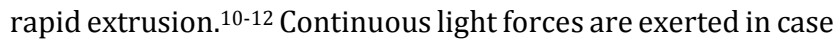
of slow orthodontic extrusion. However, there can be a reversal of osseous architecture around the subject tooth. ${ }^{13}$ In rapid extrusion, there is stretching and readjustment of the periodontal fibres, but it is not accompanied with bone remodelling due to the rapid movement. Therefore, there is no 
coronal movement of the bone and hence no need for reshaping the bone, facilitating the ease for the prosthetic treatment. ${ }^{14}$

Orthodontic tooth extrusion was preferred over crown lengthening in this clinical scenario as the later might have led to pocket formation. ${ }^{15}$ This procedure had to be performed with utmost care as evidence from literature has shown complications such as ankylosis or hypercementosis. Studies have also shown that extra load can also cause intrusion or vertical fracture of the anchor teeth. ${ }^{16}$

The material used for this case are usually available with general dentists and therefore can be easily practiced.

\section{FINAL DIAGNOSIS}

Ellis Class VIII fracture in relation to 44

\section{CONCLUSIONS}

In this case, tooth extrusion was opted as the treatment of choice as it was more conservative and economical. The procedure also overcomes the disadvantage of psychological trauma associated with extraction. This multidisciplinary approach helped in regaining the optimal crown height supragingivally, which is considered to be essential for the placement of finish lines. The procedure when followed under favourable conditions can enable the dentist to achieve predictable aesthetics and structural durability.

Financial or other competing interests: None.

Disclosure forms provided by the authors are available with the ful text of this article at jemds.com.

\section{REFERENCES}

[1] Mittal R, Gupta S, Singla A, et al. Managing sub-gingival fracture by multi-disciplinary approach: endodonticsforced orthodontic extrusion and prosthetic rehabilitation. Saudi Endodontic Journal 2013;3(2):82.

[2] Ng CC, Dumbrigue HB, Al-Bayat MI, et al. Influence of remaining coronal tooth structure location on the fracture resistance of restored endodontically treated anterior teeth. J Prosthet Dent 2006;95(4):290-6.

[3] Waginild GW, Mueller KI. Restoration of the endodontically treated tooth. Pathways of the pulp. $7^{\text {th }}$ edn. St. Louis: Mosby 1998:691-717.
[4] Heithersay GS. Combined endodontic-orthodontic treatment of transverse root fractures in region of the alveolar crest. Oral Surg Oral Med Oral Pathol 1973;36(3):404-15.

[5] Stevens BH, Levine RA. Forced eruption: a multidisciplinary approach for form, function and biologic predictability. Compend Contin Educ Dent 1998;19(10):994-1004.

[6] Simon JH, Kelly WH, Gordon DG, et al. Extrusion of endodontically treated teeth. J Am Dent Assoc 1978;97(1):17-23.

[7] Kalkan M, Usumez A, Ozturk AN, et al. Bond strength between root dentin and three glass-fiber post systems. J Prosthet Dent 2006;96(1):41-6.

[8] Ferrari M, Vichi A, García-Godoy F. Clinical evaluation of fiber-reinforced epoxy resin posts and cast post and cores. Am J Dent 2000;13(Spec No):15B-8B.

[9] Lastumäki TM, Lassila LVJ, Vallittu PK. The semi-interpenetrating polymer network matrix of fiberreinforced composite and its effect on the surface adhesive properties. J Mater Sci Mater Med 2003;14(9):803-9.

[10] Minsk L. Orthodontic tooth extrusion as an adjunct to periodontal therapy. Compend Contin Educ Dent 2000;21(9):768-70.

[11] Reitan K. Clinical and histologic observations on tooth movement during and after orthodontic treatment. Am J Orthod 1967;53(10):721-45.

[12] Bondemark L, Kurol J, Hallonsten AL, et al. Attractive magnets for orthodontic extrusion of crown-root fractured teeth. Am J Orthod Dentofacial Orthop 1997;112(2):187-93.

[13] Ingber JS. Forced eruption: alteration of soft tissue cosmetic deformities. Int J Periodontics Restorative Dent 1989;9(6):416-25.

[14] Cook MS, Scheer B. Extrusion of fractured teeth. The evolution of practical clinical techniques. Br Dent J 1980;149(2):50-3.

[15] Heda CB, Heda AA, Kulkarni SS. A multi-disciplinary approach in the management of a traumatized tooth with complicated crown-root fracture: a case report. J Indian Soc Pedod Prev Dent 2006;24(4):197-200.

[16] Nappen DL, Kohlan DJ. Orthodontic extrusion of premolar teeth: an improved technique. J Prosthet Dent 1989;61(5):549-54. 